\title{
Utilização de sulfato de bário como constituinte de concreto para blindagem de salas de radiologia
}

\section{The use of barium sulfate as a constituent of concrete for shielding of radiology rooms}

\author{
Maikon Moreira de Pires ${ }^{1}$, Chiara das Dores do Nascimento ${ }^{2}$, \\ Everton Granemann Souza ${ }^{2}$, Kaiser Kruger ${ }^{2}$, Gabriela Hoff ${ }^{3}$
}

\footnotetext{
${ }^{1}$ Universidade Católica de Pelotas, UCPel, Curso de Engenharia Civil, Rua Gonçalves Chaves, no 373, CEP: 96015-560, RS, Pelotas, Brasil.

${ }^{2}$ Programa de Pós-Graduação em Engenharia Eletrônica e Computação, PGEEC/UCPel, Rua Gonçalves Chaves, nº 373, CEP: 96015-560, RS, Pelotas, Brasil.

${ }^{3}$ Hospital de Clínicas de Porto Alegre, HCPA, Serviço de Física Médica e Radioproteção, Rua Ramiro Barcelos, nº 2350, CEP: 90035-903, RS, Porto Alegre, Brasil.

e-mail: maikon-mp@hotmail.com, chiara.nascimento@ucpel.edu.br, everton.granemann@ucpel.edu.br, kaiser_kruger@yahoo.com.br, ghoff.gesic@gmail.com
}

\begin{abstract}
RESUMO
A exposição à radiação ionizante está mais presente na rotina da sociedade atual em consequência do avanço das práticas de saúde. Desta forma, deve-se atentar aos mecanismos de proteção radiológica de modo a minimizar a radiação absorvida pelos indivíduos, principalmente em unidades de saúde. Uma sala de radiologia deve contar com uma blindagem adequada, considerando materiais com densidade e espessura apropriados. Nesse contexto, este estudo propõe um concreto específico para construção de salas de radiologia, utilizando o sulfato de bário (barita) e a rocha de basalto em sua composição. O concreto possui uma densidade aparente média de $2,46 \mathrm{~g} / \mathrm{cm}^{3}$, sendo classificado como normal, de acordo com sua densidade, evitando assim excessos de carregamento gerados pela sua estrutura. Nos testes de resistência à compressão axial característica (fck), o concreto atingiu o valor de $102,90 \mathrm{MPa}$, um aumento de $157 \%$ quando comparado ao fck para maior classe de agressividade ambiental (40 MPa), conforme estipulado pela NBR 6118. Para os ensaios de blindagem frente à radiação $\mathrm{X}$, foram moldados 5 corpos de prova prismáticos de seção transversal $10 \mathrm{~cm}$ x $10 \mathrm{~cm}$, com espessuras variando de $2 \mathrm{~mm}$ a $10 \mathrm{~mm}$. A eficácia da blindagem foi aferida por uma câmara de ionização, posicionada abaixo dos corpos de prova, para diferentes valores de energia do feixe de raios $\mathrm{X}(60,90 \mathrm{e} 125 \mathrm{kVp})$. Os resultados indicam que mesmo para $125 \mathrm{kVp}$, um dos maiores valores utilizados na maioria dos equipamentos de radiologia, uma espessura de $16,70 \mathrm{~mm}$ é suficiente para barrar $95 \%$ da radiação X, conforme recomendado pela Portaria Federal n ${ }^{\circ} 453$ da Anvisa. Esse conjunto de fatores, em especial a sua capacidade de blindagem, mostram que o concreto proposto é adequado para aplicações em blindagens de salas de radiologia.
\end{abstract}

Palavras-chave:Sulfato de bário, blindagem, radiologia, radiação ionizante.

\section{ABSTRACT}

Exposure to ionizing radiation is increasingly common in the routine of modern society, due to the advances in health practices. Thus, attention should be drawn to the mechanisms of radiological protection in order to minimize the radiation absorbed by individuals, especially in healthcare facilities. A radiology room must have adequate shielding, considering materials with the appropriate density and thickness. In this context, this study proposes a concrete specific for the construction of radiology rooms, using barium sulfate (barite) and basalt rock in its composition. The concrete has an average apparent density of $2.46 \mathrm{~g} / \mathrm{cm}^{3}$, being classified as normal, according to its density, avoiding overload generated by its structure. During resistance to axial compression characteristic (fck) tests, the concrete reached the value of $102.90 \mathrm{MPa}$. This value represents an increase of $157 \%$ when compared to fck for a higher class of environmental aggressiveness (40 $\mathrm{MPa}$ ), as provided in NBR 6118. For the radiation shielding tests, 5 prismatic samples with area $10 \mathrm{~cm} \times 10$ $\mathrm{cm}$, and thicknesses varying from $2 \mathrm{~mm}$ to $10 \mathrm{~mm}$, were molded. The shielding efficiency was measured by an ionization chamber, positioned below the samples, for different energy values of the X-ray beam (60, 90 and $125 \mathrm{kVp}$ ). The results indicate that even for $125 \mathrm{kVp}$, one of the highest values used in most radiology equipment, a thickness of $16.70 \mathrm{~mm}$ is sufficient to block $95 \%$ of X-radiation, as recommended by the 
Federal Ordinance No. 453 of Anvisa. This set of factors, in particular its shielding capacity, shows that the proposed concrete is suitable for applications in radiology room shielding.

Keywords: Barium sulfate, shielding, radiology, ionizing radiation.

\section{INTRODUÇÃO}

A radiologia surgiu em 1895, com o físico alemão Wilhelm Conrad Roentgen, através da realização da primeira radiografia. Este experimento proporcionou um avanço na área da saúde, devido à sua aplicabilidade em exames médicos [1].

O uso crescente das radiações ionizantes ocasionadas pelo avanço tecnológico, impulsionou organizações nacionais e internacionais a estabelecerem recomendações para a proteção dos indivíduos e do meio ambiente, em relação aos efeitos danosos causados por estas radiações [2].

Visando proteger as pessoas contra as radiações ionizantes, principalmente em unidades de saúde, a utilização de novos compostos vem sendo estudada por diversos pesquisadores da área de forma a obter alternativas aos materiais já utilizados em barreiras protetoras (também conhecidas como blindagens) como o chumbo, o concreto e o ferro [3]. Por se tratarem de partes indispensáveis para a proteção e operação em instalações de equipamentos geradores estão, dentre os componentes utilizados na construção civil das salas, os que têm maior impacto sobre os custos das obras [4].

Helene e Andrade destacam que o concreto de cimento Portland é o material estrutural e de construção civil mais importante da atualidade. Mesmo sendo um material ainda recente no ramo das construções estruturais, pode ainda ser considerado como uma das grandes descobertas para a contribuição do desenvolvimento da humanidade e de sua qualidade de vida [5]. Para tanto, deve-se atentar para aplicação consciente dos recursos naturais disponíveis atualmente, visando o emprego de menores níveis de consumo de recursos, como o de cimento, por exemplo [6].

Uma alternativa para otimizar a concepção de uma sala de radiologia é deter-se ao estudo particular do concreto a ser utilizado na sua construção. A falta de estudos específicos de dosagens deste tipo de concreto acarreta na inexistência de curvas de atenuação apropriadas, o que por consequência, contra indicam sua utilização de rotina. Atualmente, no processo construtivo das referidas salas, são utilizados concretos comuns, ou seja, objetiva-se em atingir a espessura desejada independente do material utilizado na mistura [4].

Sendo assim, esta pesquisa tem como objetivo principal a obtenção de um concreto eficaz, quanto da blindagem à radiação, e viável, quanto da obtenção dos agregados, para aplicação na construção de salas de radiologia. Para isso foi elaborado um traço a base de sulfato de bário e cimento Portland.

Com intuito de comprovar a eficácia da aplicação do composto, avaliou-se a sua resistência característica à compressão axial com 28 dias de idade, sua densidade aparente e por fim, sua a capacidade de atenuação da radiação ionizante para blocos de concreto de $2 \mathrm{~mm}$ à $10 \mathrm{~mm}$ de espessura.

Os resultados indicam que utilizando uma configuração de energia próxima do máximo estabelecido pelo equipamento de raios $\mathrm{X}(125 \mathrm{kVp})$ uma espessura de $16.70 \mathrm{~mm}$ é suficiente para barrar $95 \%$ da radiação, estando em conformidade com o exigido pela Portaria Federal n ${ }^{\circ} 453$ da Anvisa [7]

Com base nesses aspectos, o trabalho mostra-se relevante pois propõe um estudo de viabilidade de um concreto capaz de blindar a radiação ionizante proveniente de um aparelho de raios X.

\section{MATERIAIS E MÉTODOS}

O sulfato de bário natural (ou barita) é um mineral de constituição inorgânica, quimicamente inerte, extraído de jazidas e beneficiado em diversas faixas granulométricas de acordo com a aplicação desejada. Possui fórmula química $\mathrm{BaSO}_{4}$ e sua densidade pode variar de acordo com a amostra da barita utilizada, podendo ser barita branca bruta $\left(3,79 \mathrm{~g} / \mathrm{cm}^{3}\right)$, barita branca mista $\left(3,10 \mathrm{~g} / \mathrm{cm}^{3}\right)$, barita roxa bruta $\left(2,99 \mathrm{~g} / \mathrm{cm}^{3}\right)$, entre outras . Por apresentar elevada densidade é amplamente utilizado para aumentar a referida característica em outros materiais, como por exemplo, em tintas e derivados do petróleo, e ainda, em materiais isolantes para tratamentos radiológicos [2], como no caso deste estudo.

A barita utilizada nesse trabalho é do tipo branca bruta $(98,46 \%$ de pureza - empresa Minérios Ouro Branco, Vila Nova Cachoeirinha, São Paulo - SP), ilustrada na Figura 1 


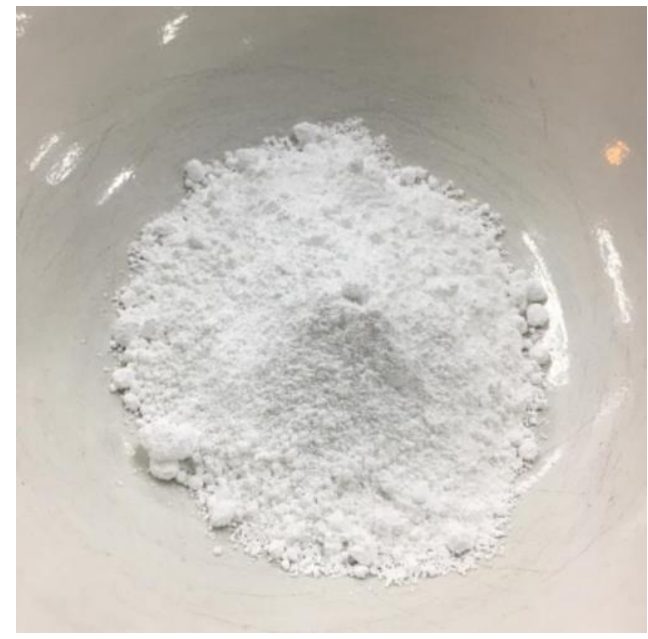

Figura 1: Sulfato de bário em pó $\left(\mathrm{BaSO}_{4}\right)$ ou barita branca bruta.

O basalto é uma rocha ígnea eruptiva (magmática) de composição máfica, rica em silicatos de magnésio e ferro, o que constitui uma das rochas mais abundantes na crosta terrestre. O basalto, pela sua dureza e resistência à meteorização, é explorado para a produção de alvenarias e de agregados de construção civil e como rocha ornamental para revestimentos e calçadas. A produção de fibras de basalto é uma indústria em expansão [8].

Por outro lado, o cimento utilizado foi do tipo ARI (alta resistência inicial) classe CPV por apresentar menor teor de adições (mais puro) e também por proporcionar concretos mais duráveis. Suas características químicas estão apresentadas na tabela 1 conforme indicado pelo fabricante do cimento (Votoran).

Tabela 1: Propriedades químicas do cimento, segundo dados do fabricante.

\begin{tabular}{|c|c|c|}
\hline \multirow[b]{2}{*}{ COMPOSIÇÃO QUÍMICA } & \multicolumn{2}{|c|}{ CPV ARI } \\
\hline & $\begin{array}{l}\text { VALOR } \\
(\%)\end{array}$ & LIMITES \\
\hline Trióxido de enxofre (SO3) & 3,15 & $\leq 4,5$ \\
\hline Óxido de magnésio $(\mathrm{MgO})$ & 4,99 & $\leq 6,5$ \\
\hline Óxido de aluminio $\left(\mathrm{Al}_{2} \mathrm{O}_{3}\right)$ & 4,24 & - \\
\hline Óxido de silício $\left(\mathrm{SiO}_{2}\right)$ & 19,06 & - \\
\hline Óxido de ferro $\left(\mathrm{Fe}_{2} \mathrm{O}_{3}\right)$ & 2,58 & - \\
\hline Óxido de cálcio $(\mathrm{CaO})$ & 60,23 & - \\
\hline Perda ao fogo & 3,24 & $\leq 6,5$ \\
\hline Resíduo insolúvel & 0,68 & $\leq 6,5$ \\
\hline Óxido de cal livre ( $\mathrm{CaO}$ livre $)$ & 1,43 & - \\
\hline Equivalente alcalino & 0,59 & - \\
\hline
\end{tabular}

Limites Normativos - NBR 16697 (ABNT, 2018)

De forma a avaliar as dimensões das partículas dos agregados utilizados na mistura (cimento CPV e barita) foi realizada uma análise granulométrica através de difração de laser (CILAS modelo 1064). Para diâmetros maiores que $149 \mu \mathrm{m}$, como no caso do basalto em areia e em pó, foi utilizado uma série de peneiras padrão, seguindo as prescrições de ensaio estabelecidos na NBR NM 248 [9]. A tabela 2 exibe os diâmetros médios de cada matéria prima, assim como as frações encontradas no intervalo estatístico.

Em seguida, foi realizado o ensaio de determinação da densidade real dos agregados. Este ensaio tem como objetivo avaliar e quantificar a densidade real e efetiva do material ensaiado de acordo com a normativa DNER-ME 093/94 [10]. Parte deste ensaio está ilustrado na Figura 2. 
Tabela 2: Granulometria das matérias primas utilizadas no concreto.

\begin{tabular}{c|c|c|c|c}
\hline MATERIAL & $\begin{array}{c}\text { DIÂMETRO } \\
\text { MÉDIO }(\mu \mathrm{m})\end{array}$ & $\begin{array}{c}\text { DIÂMETRO } \\
\text { DE 10\% } \\
(\mu \mathrm{m})\end{array}$ & $\begin{array}{c}\text { DIÂMETRO } \\
\text { DE 50\% } \\
(\mu \mathrm{m})\end{array}$ & $\begin{array}{c}\text { DIÂMETRO } \\
\text { DE 90\% } \\
(\mu \mathrm{m})\end{array}$ \\
\hline Cimento CPV - ARI & 51,88 & 13,16 & 53,47 & 82,38 \\
\hline Sulfato de Bário & 51,00 & 2,12 & 55,16 & 85,65 \\
\hline $\begin{array}{c}\text { Areia Artificial de } \\
\text { Basalto }\end{array}$ & 297,00 & - & - & - \\
\hline Pó de Basalto & 149,00 & - & - & - \\
\hline
\end{tabular}

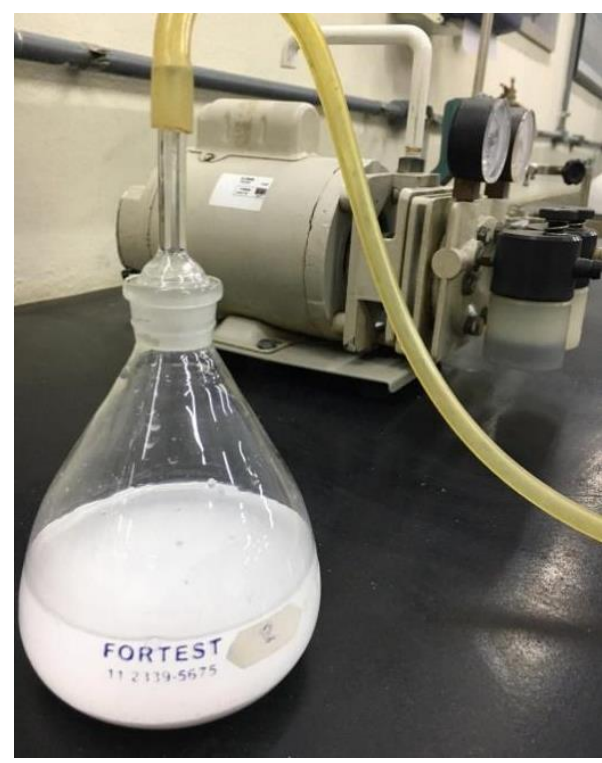

Figura 2: Ensaio de densidade real para o sulfato de bário.

A Tabela 3 apresenta os resultados obtidos para cada matéria prima de acordo com o ensaio de determinação da densidade real dos grãos. Os valores estão indicados em grama por centímetro cúbico $\left(\mathrm{g} / \mathrm{cm}^{3}\right)$.

Tabela 3: Densidade real dos materiais utilizados.

\begin{tabular}{c|c}
\hline MATERIAL & DENSIDADE REAL $\mathbf{( g / \mathbf { c m } ^ { 3 } )}$ \\
\hline Cimento CPV - ARI & 3,06 \\
\hline Sulfato de Bário & 3,73 \\
\hline Areia Artificial de Basalto & 3,27 \\
\hline Pó de Basalto & 2,58 \\
\hline
\end{tabular}

Para determinação das relações unitárias utilizou-se como referência o método Unisinos de dosagem para concretos de ultra alto desempenho (UHPC). Este método consiste em obter o melhor empacotamento entre diferentes materiais presentes na mistura utilizando o modelo de empacotamento de partículas proposto por Funk e Dinger que determina a quantidade em porcentagem de um determinado diâmetro ideal a ser empregado na mistura [11].

Através deste método proposto e ainda, com testes experimentais em laboratório para verificação das proporções adotadas, obteve-se as seguintes relações unitárias para o traço denominado "traço padrão", conforme apresenta a Tabela 4. 
Tabela 4: Traço padrão - composições unitárias.

TRAÇO PADRÃO

\begin{tabular}{c|c}
\hline MATERIAL & TRAÇO UNITÁRIO \\
\hline Aditivo Superplastificante PowerFlow 1180 & 0,03 \\
\hline Água & 0,25 \\
\hline Areia Artificial de Basalto & 0,55 \\
\hline Cimento CPV - ARI & 1,00 \\
\hline Pó de Basalto & 0,70 \\
\hline Sulfato de Bário & 0,30 \\
\hline
\end{tabular}

Em seguida, foram moldados 5 (cinco) corpos de prova prismáticos de dimensões $10 \mathrm{~cm}$ x $10 \mathrm{~cm}$ com a espessura variando de $2 \mathrm{~mm}$ em $2 \mathrm{~mm}$, partindo de uma espessura mínima de $2 \mathrm{~mm}$ até uma espessura máxima de 10 mm. Estes corpos de provas (CP’s) estão ilustrados na Figura 3.

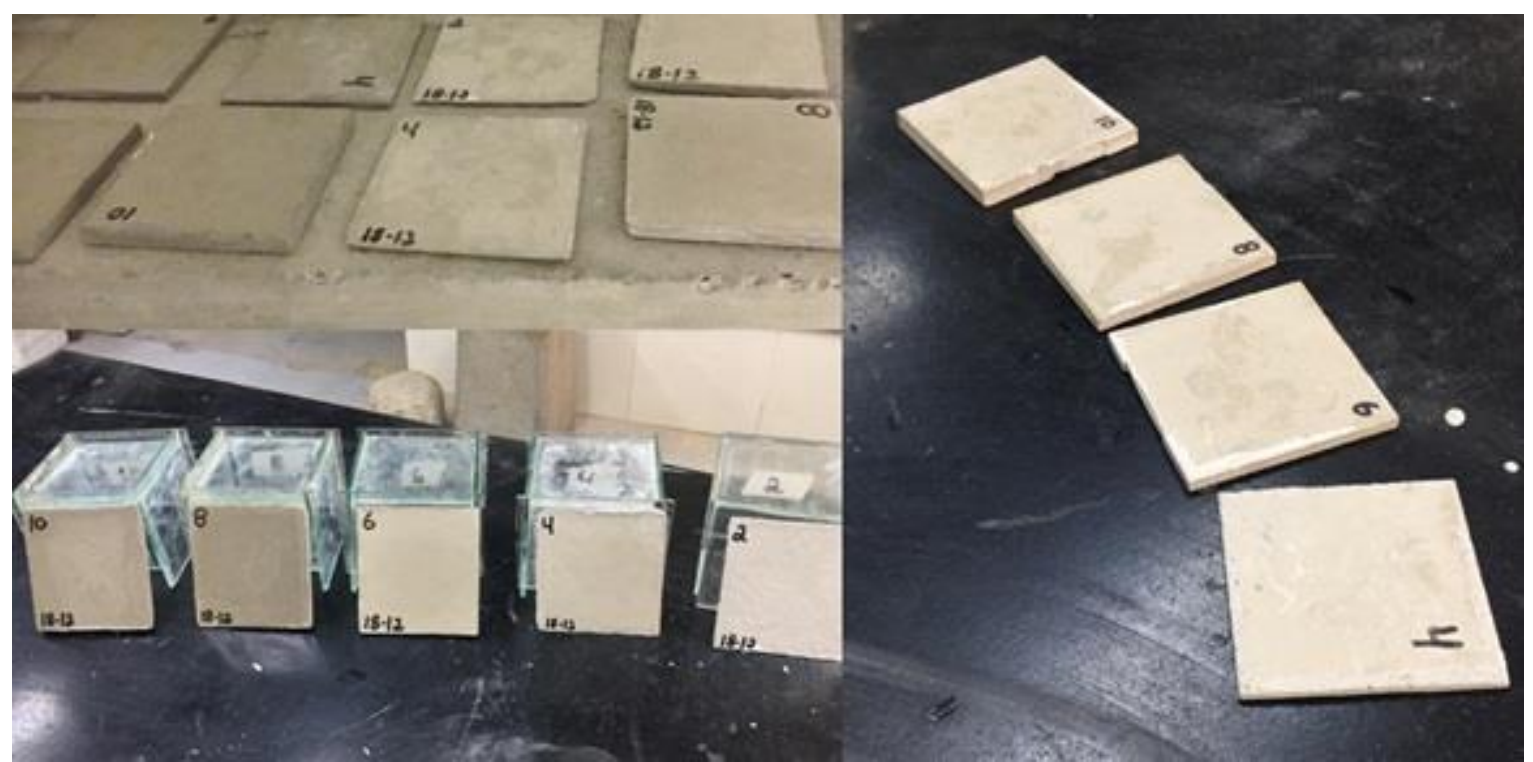

Figura 3: Corpos de prova prismáticos do traço padrão.

Nas primeiras 48 h de cura, conforme estipulado pela NBR 5738, os corpos de prova permaneceram em temperatura ambiente. Após este período os mesmos foram deformados com todo o cuidado, de forma a não causar nenhum dano. Em seguida, os corpos de prova foram curados por 28 dias em câmara úmida com temperatura controlada de $(23 \pm 2)^{\circ} \mathrm{C}$, seguindo o protocolo estabelecido pela NBR 9479 [12].

Para garantir uma equivalência entre as características construtivas das amostras, foram utilizados produtos da mesma marca (cimento CPV Votoran, sulfato de bário Neon e rocha de basalto Pedraccon Mineração), com as amostras sendo confeccionadas no mesmo dia e sob as mesmas condições de temperatura.

A eficácia da blindagem radioativa de cada corpo de prova foi avaliada por uma câmara de ionização da Radcal Corporation, Modelo 9010, posicionada atrás de cada amostra em relação a fonte de emissão de raios $\mathrm{X}$ (tubo de raios-X), de forma a mensurar a radiação transmitida através do referido $\mathrm{CP}$ de concreto. A câmara de ionização utilizada nesse estudo está ilustrada na Figura 4 posicionada junto a uma amostra de concreto de $6 \mathrm{~mm}$, no lado oposto a face exposta à radiação.

Para os ensaios radiológicos foram escolhidas as energias cinéticas do tubo de raios-X (quilovoltagem pico) de 60, 90 e $125 \mathrm{kVp}$. Tais valores escolhidos da quilovoltagem pico estão associados com o mínimo, máximo e um valor intermediário utilizados em equipamentos de raios $\mathrm{X}$ durante exames de radiologia com pacientes. Para esses valores de $\mathrm{kVp}$, a dose máxima aplicada aos corpos de prova foi de $40 \mathrm{mR}$ (miliroentgen), $87 \mathrm{mR}$ e $153 \mathrm{mR}$, respectivamente. 


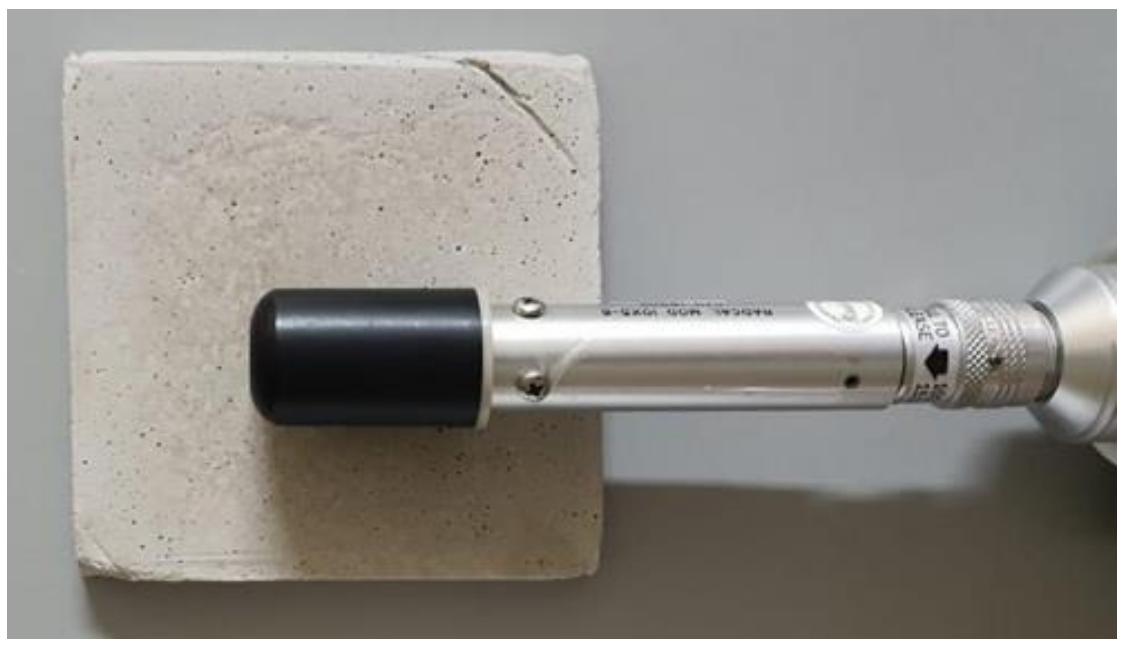

Figura 4: Câmara de ionização (Radcal Corporation) sobre o corpo de prova do traço padrão.

Além dos corpos de prova prismáticos, foram moldados 6 corpos de prova cilíndricos para determinar as resistências à compressão axial e também, as densidades aparentes do concreto proposto. Com $5 \mathrm{~cm}$ de diâmetro e $10 \mathrm{~cm}$ de altura, os CP's foram rompidos uma metade com 7 dias e a outra metade com 28 dias de idade.

Para determinar a densidade aparente de cada CP cilíndrico foi realizada a razão da massa pelo volume do respectivo molde. Com o auxílio de uma balança de precisão, foram obtidas as massas em gramas dos 6 corpos de prova cilíndricos e na sequência, realizada a razão pelo volume dos moldes. Desta forma, o resultado final de densidade aparente do concreto proposto nesta pesquisa, será o valor médio das densidades aparentes obtidas para cada um dos 6 corpos de prova, moldados sobre as mesmas condições.

A fim de determinar os valores de resistência à compressão obtidos, as amostras cilíndricas foram ensaiadas na sua integralidade conforme descreve a NBR 5739 [13]. Após o posicionamento dos CP's na prensa (marca WPM, modelo 300b, com capacidade de $300 \mathrm{t}$ ) foram posicionados pratos, nas faces inferior e superior, a fim de arrematar os CP's para receberem forças verticais de forma distribuída.

Na sequência, a prensa hidráulica foi acionada com aplicação de carga contínua, e sem choque sobre o $\mathrm{CP}$, com velocidade de carregamento de $0,45 \mathrm{MPa} / \mathrm{s}$. Esta velocidade foi mantida enquanto o $\mathrm{CP}$ Sofria deformação, até atingir a sua ruptura. $\mathrm{O}$ valor final de resistência à compressão foi obtido dividindo a carga de ruptura pela área da seção transversal do corpo de prova. A prensa hidráulica utilizada no ensaio de resistência à compressão axial, assim como, os corpos de prova em seu estado normal e rompido estão ilustrados nas Figuras 5, 6, 7 e 8.

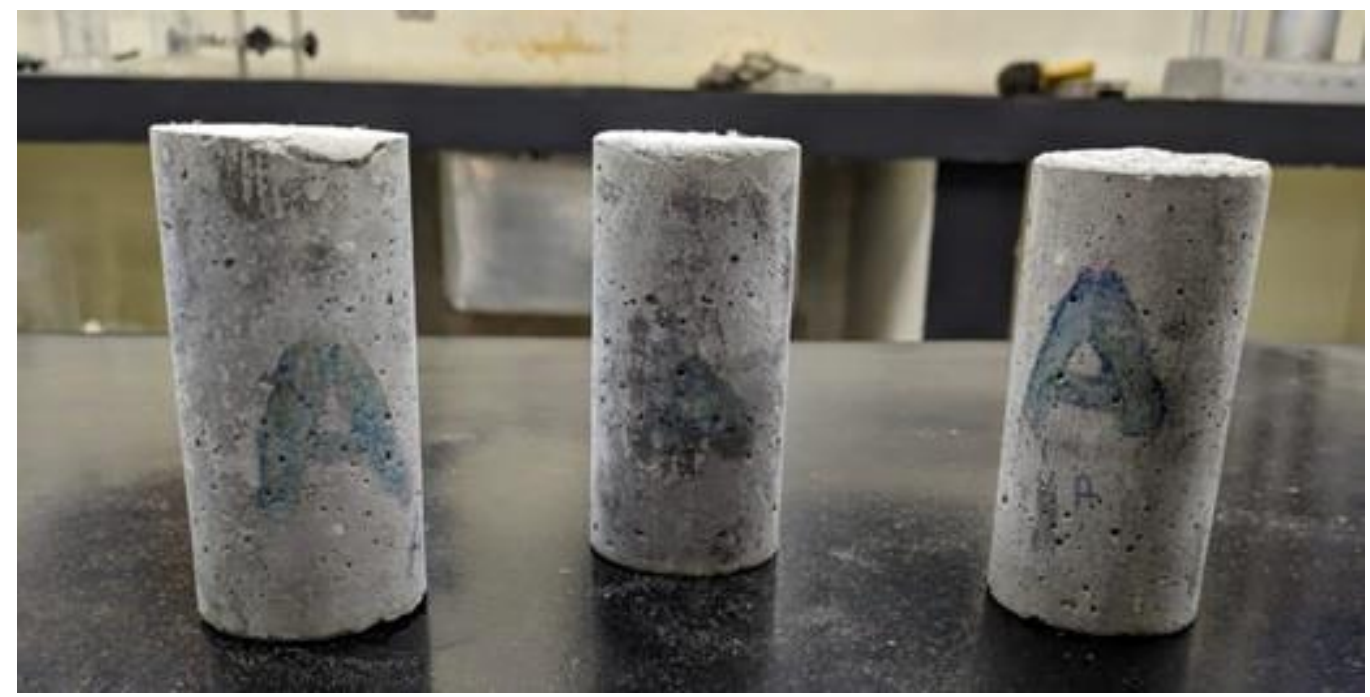

Figura 5: Corpos de prova cilíndricos do traço padrão. 


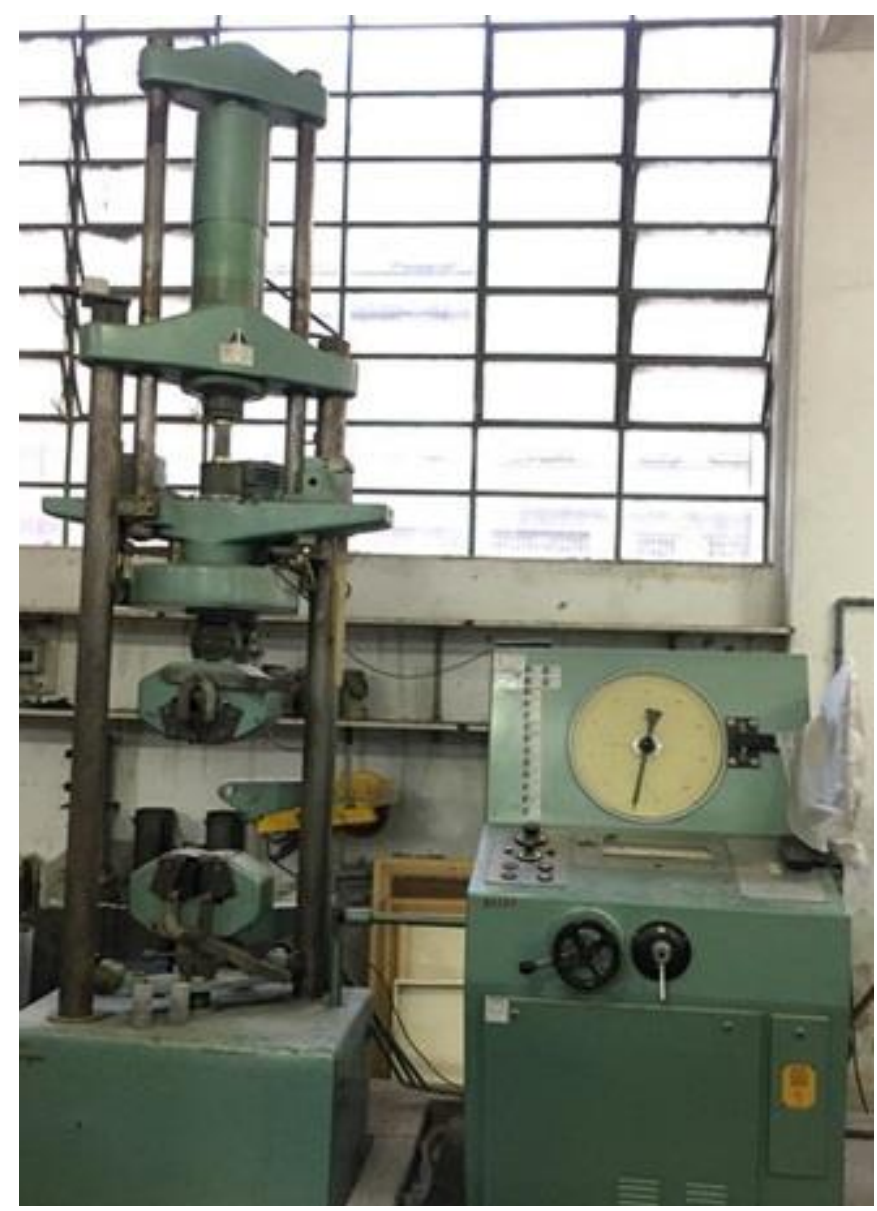

Figura 6: Prensa hidráulica no rompimento do corpo de prova cilíndrico.

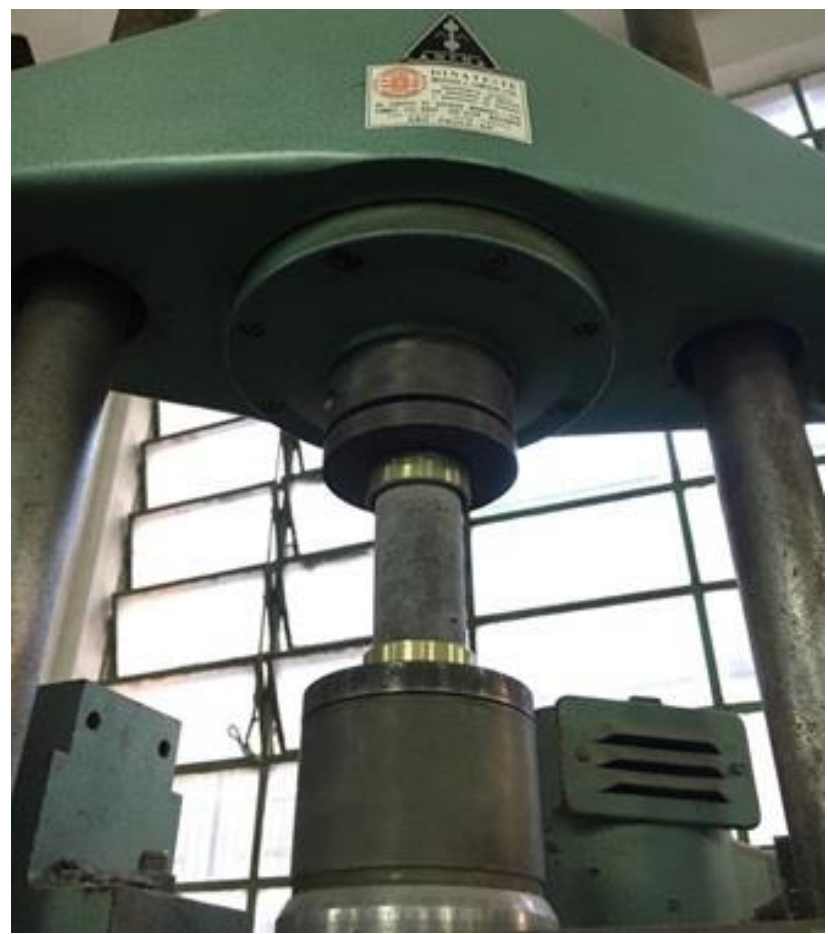

Figura 7: Corpo de prova em processo de rompimento na prensa hidráulica. 


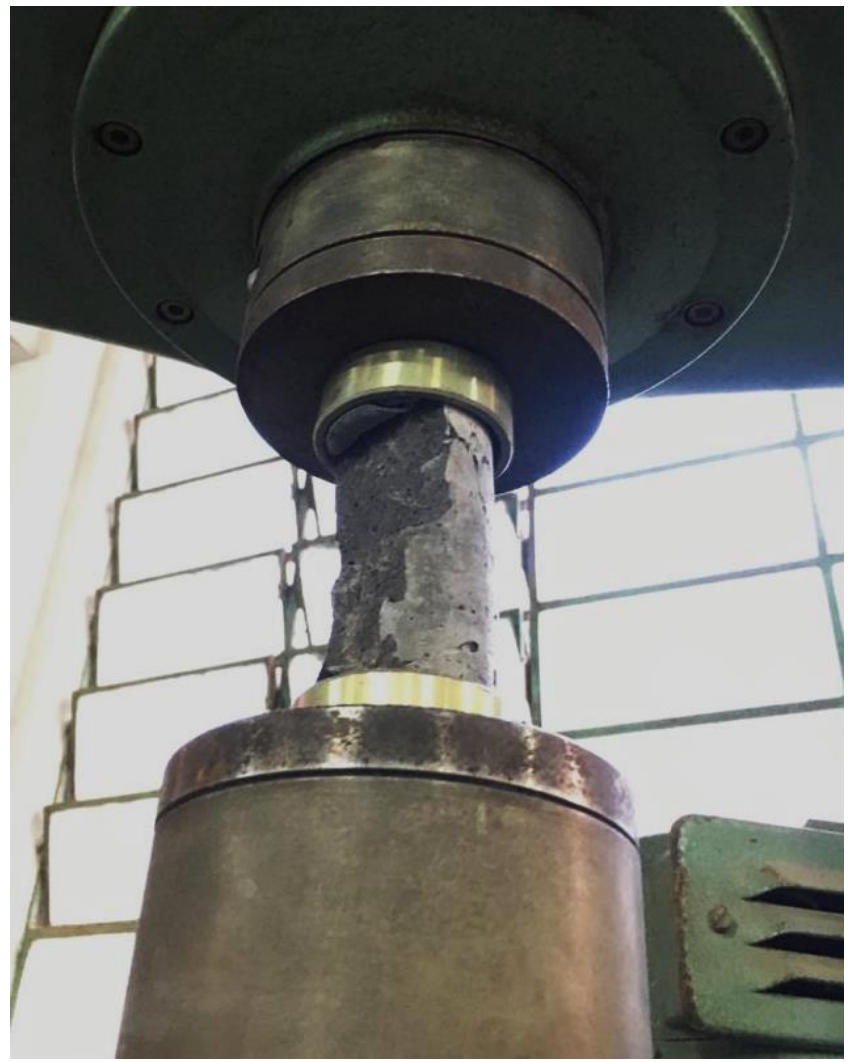

Figura 8: Corpo de prova rompido/colapsado na prensa hidráulica.

\section{RESULTADOS E DISCUSSÕES}

Na Tabela 5 estão dispostos os valores das densidades aparentes obtidas para cada corpo de prova cilíndrico, assim como, o valor da densidade aparente final obtida para o concreto proposto neste estudo, elaborado com o traço padrão.

Tabela 5: Densidade obtida para o traço padrão.

\section{DENSIDADE APARENTE - TRAÇO PADRÃO}

\begin{tabular}{c|c}
\hline $\mathbf{C P}$ & $\mathbf{g} / \mathbf{c m}^{\mathbf{3}}$ \\
\hline 1 & 2,42 \\
\hline 2 & 2,46 \\
\hline 3 & 2,47 \\
\hline 4 & 2,44 \\
\hline 5 & 2,49 \\
\hline 6 & 2,51 \\
\hline Média \pm Desvio Padrão & $\mathbf{2 , 4 6 \pm 0 . 0 3}$ \\
\hline
\end{tabular}

Com base nos resultados da Tabela 4, obteve-se uma densidade média aparente de $2,46 \mathrm{~g} / \mathrm{cm}^{3}$ sobre seis medidas para o traço padrão, sendo este classificado como "normal" de acordo com a NBR 8953 [14].

Diferentemente dos concretos pesados (densidade superior a $2,80 \mathrm{~g} / \mathrm{cm}^{3}$ ) o novo composto por ser considerado "normal", viabiliza um menor carregamento da estrutura construída com este material. Estruturas menos carregadas impactam em fundações significativamente menores além de proporcionarem 
um melhoramento na concepção do projeto como um todo.

Os resultados obtidos para o ensaio de resistência à compressão axial estão ilustrados na Figura 9, onde com 7 dias de idade o concreto obteve 94,07 MPa e com 28 dias de idade a resistência atingiu 100,19 MPa. Os resultados apresentados para cada idade são os valores médios obtidos do rompimento de três corpos de prova cilíndricos.

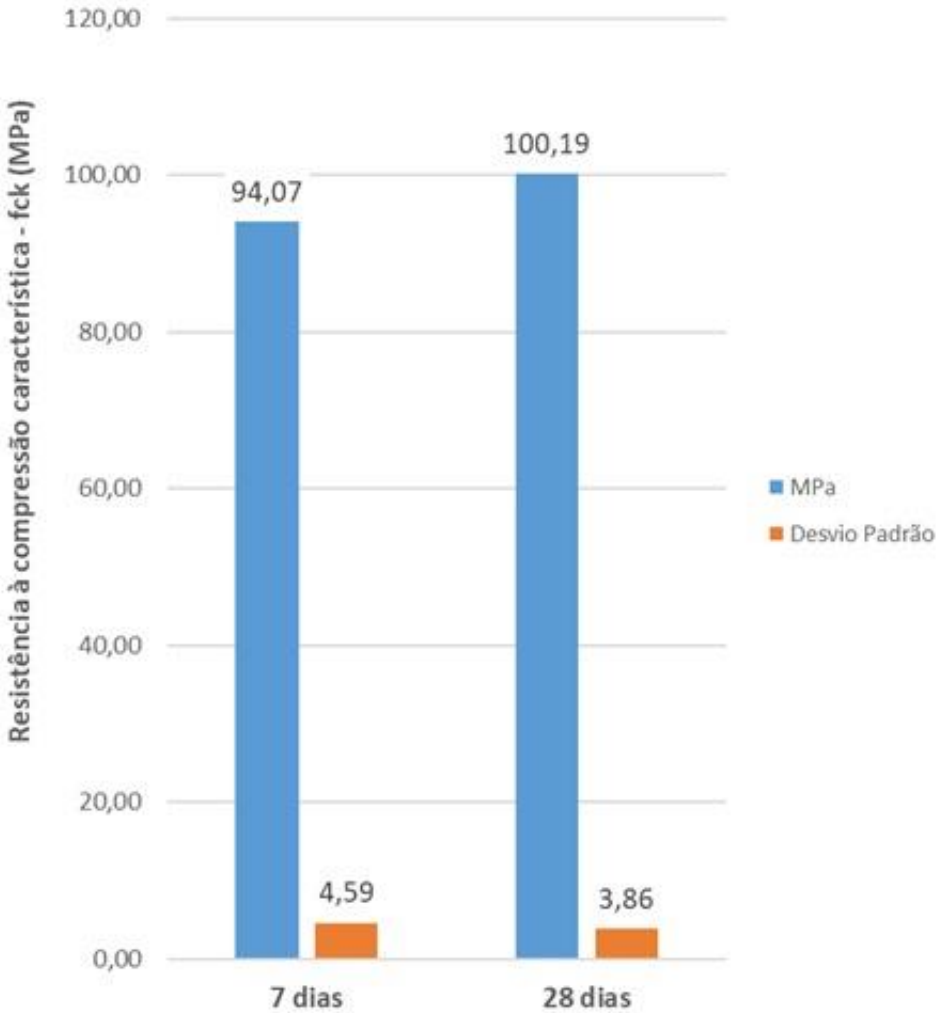

Figura 9: Resistências características dos concretos à compressão axial em MPa.

Estes resultados foram obtidos nas duas idades a fim de avaliar a evolução da resistência à compressão axial neste período. No entanto, a resistência característica do concreto (fck) é dada aos 28 dias. Portanto, o fck obtido para o traço padrão foi de 102,90 MPa.

$\mathrm{O}$ cimento aplicado nesta pesquisa foi o da classe CPV, também denominado cimento ARI (Alta Resistência Inicial). Este aglomerante possui alta reatividade em baixas idades por ser um material mais puro, ou seja, possui menor teor de adições. Dessa forma, a evolução e o ganho da resistência à compressão axial dos 7 dias para os 28 dias foram de apenas 3,58\%, justificada pelo emprego do cimento em questão.

A NBR 6118 [15], de acordo com a exposição ambiental das estruturas de concreto, define as classes de agressividades, assim como, as resistências mínimas à compressão (fck) a serem atingidas e respeitadas pelo concreto de acordo com sua aplicação.

A mesma normativa ainda divide os concretos em protendidos e armados, sendo o último aplicado na construção de uma sala de radiologia, por exemplo. Para concretos armados estruturais a resistência mínima a ser atingida é de $30 \mathrm{MPa}$. No entanto, se esta estrutura estiver localizada na classe de agressividade ambiental mais severa (classe IV) a resistência mínima deve ser de $40 \mathrm{MPa}$.

Sendo assim, é possível observar que o fck obtido para o concreto proposto (102,90 MPa), atende aos critérios estruturais e de severidade do meio conforme estipulado pelas normativas vigentes, tendo superado os valores mínimos em mais de $157 \%$.

$\mathrm{O}$ comportamento dos CP's frente à exposição à radiação ionizante está ilustrado nas Figuras 10, 11 e 12, que relacionam a espessura dos CP's com a intensidade de radiação transmitida. Cada ponto nessas Figuras representa uma média sobre cinco medidas experimentais, e em todos os casos, o desvio padrão foi inferior a $0,68 \%$.

Vale ressaltar que a radiação emitida pela fonte de raios X é dividida em partes: atenuada e transmitida. A parte atenuada é aquela absorvida pelo CP, responsável pela eficácia da blindagem. Já a parte transmitida, representa o que atravessou o $\mathrm{CP}$ e, por consequência, a radiação que ele não foi capaz de ser blindar.

A atenuação da radiação ionizante para os CP's de $2 \mathrm{~mm}, 4 \mathrm{~mm}, 6 \mathrm{~mm}, 8 \mathrm{~mm}$ e $10 \mathrm{~mm}$ foram, 
respectivamente, de 70\%,79\%,90\%,95\% e 97\% para a energia cinética de $60 \mathrm{kVp}$, conforme mostra a Figura 10. De acordo com a Portaria Federal $n^{\circ} 453$ da Anvisa [7], a atenuação da radiação ionizante admissível para espaços acessíveis a indivíduos deve ser de no mínimo 95\%. Assim, para os CP's com espessura de 10 mm, esta condição de segurança é atendida, conforme indica a Figura 10.

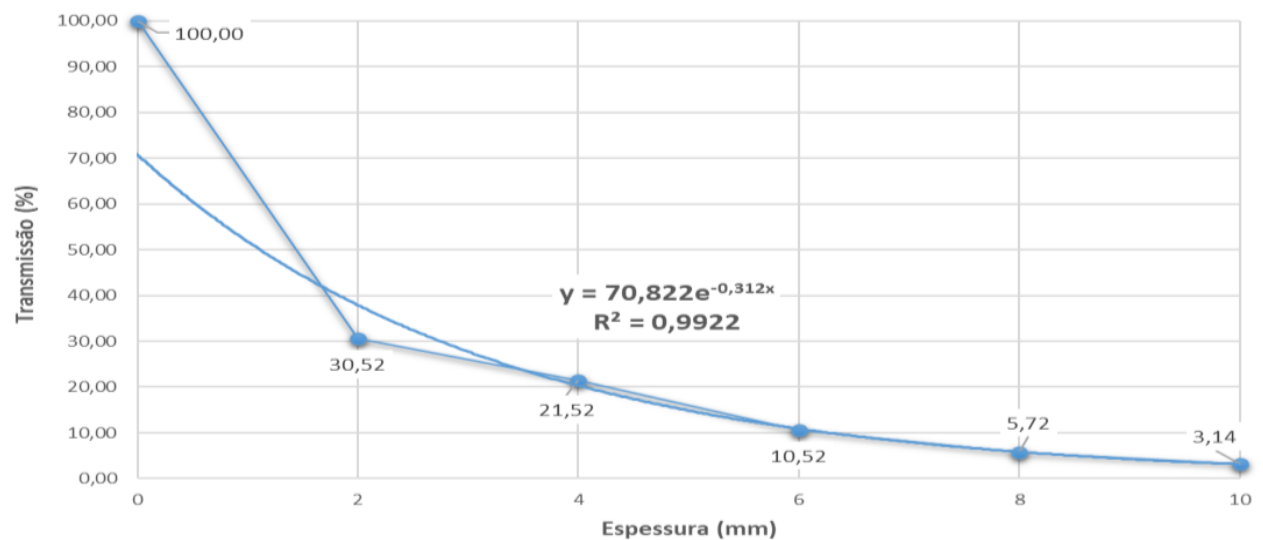

Figura 10: Radiação transmitida, em porcentagem, versus espessura dos corpos de prova, em milímetros, para uma energia de $60 \mathrm{kVp}$.

A radiação incidida em um material diminui exponencialmente à medida que aumentamos sua a espessura, conforme previsto pela Lei de Beer-Lambert [16] vista na Equação 1:

$$
I=I_{0} e^{-k x}
$$

$\mathrm{O} \mathrm{I}_{0}$ representa a intensidade de radiação do feixe de raios $\mathrm{X}$ incidente nos $\mathrm{CP}$ 's e $\mathrm{I}$ é a intensidade transmitida por esse mesmo feixe após ser atenuada por qualquer um dos CP's para uma determinada espessura x. O parâmetro k é denominado coeficiente de atenuação e controla a velocidade de queda da curva exponencial. Quanto maior o valor de $\mathrm{k}$, mais eficaz é a atenuação da radiação à medida que se aumenta a espessura.

Se considerarmos que a aquisição da intensidade transmitida foi realizada pela câmara de ionização no mesmo intervalo de tempo para todas as amostras, ela segue os princípios da Lei de Beer-Lambert. Esse resultado está exibido nas Figuras 10 (e também nas Figuras 11 e 12), na forma normalizada e em escala percentual, ou seja, dividida pela intensidade da fonte sem a blindagem e multiplicada por 100. Através do ajuste exponencial, obteve-se um coeficiente de atenuação $\mathrm{k}=0,312$ para energia cinética de $60 \mathrm{kVp}$.

Já para energia cinética de $90 \mathrm{kVp}$ as atenuações obtidas foram de 59\%,68\%, 81\%, 87\% e 91\%, para as espessuras de $2 \mathrm{~mm}, 4 \mathrm{~mm}, 6 \mathrm{~mm}, 8 \mathrm{~mm}$ e $10 \mathrm{~mm}$, respectivamente. Os referidos resultados podem ser verificados na Figura 11.

Ainda na Figura 11, é possível observar que para energia cinética de $90 \mathrm{kVp}, \mathrm{k}=0,221$. Em comparação com o coeficiente apresentando para a energia cinética de $60 \mathrm{kVp}$, este índice teve um decréscimo de $29 \%$, aproximadamente, justificado pelo aumento da energia do equipamento de raios-X.

Por fim, para a energia cinética de $125 \mathrm{kVp}$ um limite máximo para a maioria dos exames de radiologia, considerando ainda os mesmos corpos de prova citados anteriormente, as atenuações foram de $49 \%, 58 \%$, $71 \%, 79 \%$ e 84\%, conforme demonstra na Figura 12.

Observa-se ainda que o ajuste exponencial para energia de $125 \mathrm{kVp}$, apresenta o maior distanciamento, em y em relação à origem do plano. Ou seja, apresentou a menor velocidade de queda com um coeficiente de atenuação $\mathrm{k}=0,169$. O valor de $\mathrm{k}$ decresceu aproximadamente $46 \%$ quando comparado com a energia de 60 $\mathrm{kVp}$, e $24 \%$ em comparação com o equipamento operando em $90 \mathrm{kVp}$. Essa diminuição do coeficiente era esperada tendo em vista o aumento progressivo da energia cinética do tubo de raios-X. 


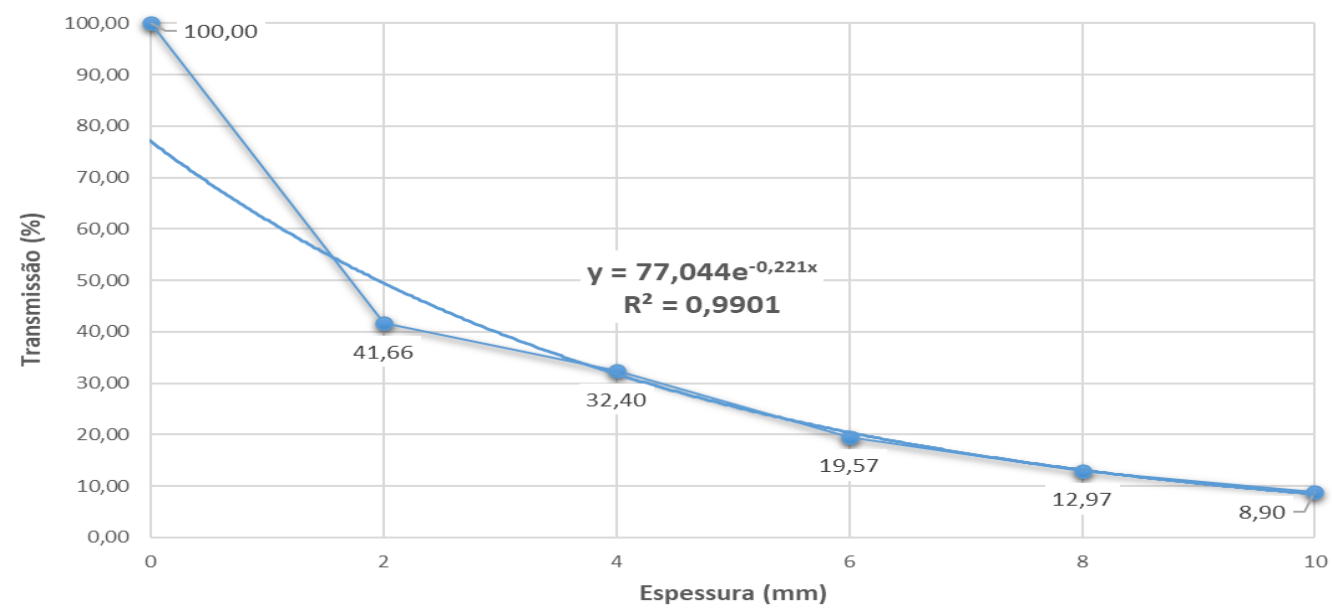

Figura 11: Radiação transmitida em porcentagem versus espessuras dos corpos de prova em milímetros, para uma energia de $90 \mathrm{kVp}$.

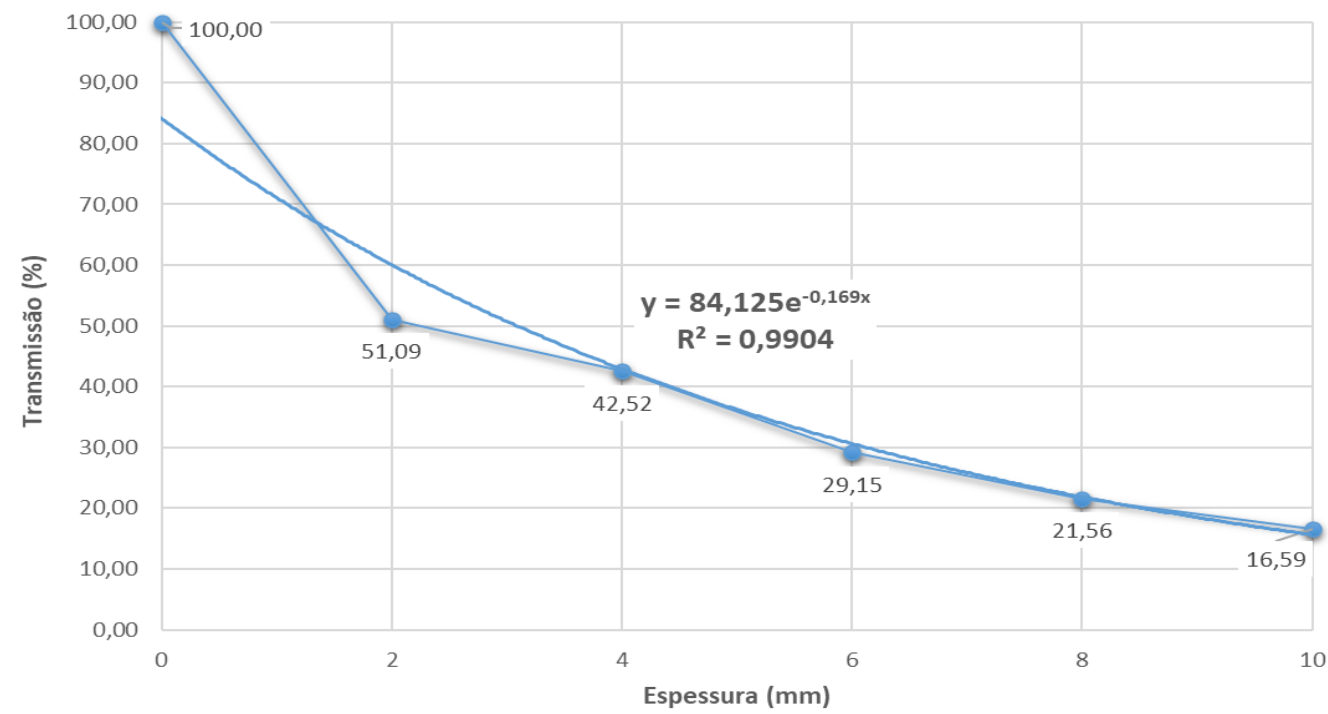

Figura 12: Radiação transmitida em porcentagem versus espessuras dos corpos de prova em milímetros, para uma energia de $125 \mathrm{kVp}$.

\section{CONCLUSÕES}

Neste estudo foi apresentada a viabilidade do uso do sulfato de bário como constituinte de concreto para aplicação em blindagens de radiação $\mathrm{X}$ em salas de radiologia.

Para comprovar a eficácia da blindagem, foram fabricadas amostras de concreto com um traço com barita na sua constituição, com espessuras de $2 \mathrm{~mm}, 4 \mathrm{~mm}, 6 \mathrm{~mm}, 8 \mathrm{~mm}$ e $10 \mathrm{~mm}$, as quais foram irradiadas por diferentes energias $(60,90$ e $125 \mathrm{kVp})$. Tais energias foram escolhidas a partir da radiação transmitida ao paciente em exames reais, considerando uma dose recebida de mínima, média e máxima.

Os gráficos de atenuação mostram que, para a menor energia escolhida, de $60 \mathrm{kVp}$, a atenuação com uma espessura de $10 \mathrm{~mm}$ foi de $97 \%$ (Figura 10). Já para a energia intermediária, de $90 \mathrm{kVp}$, e máxima, 125 $\mathrm{kVp}$, foram obtidas atenuações de $91,1 \%$ e $84 \%$, respectivamente. Assim, para a energia de $125 \mathrm{kVp}$, seria necessária uma espessura de concreto de $16,70 \mathrm{~mm}$ para que a concepção da sala de radiologia estivesse de acordo com a Portaria Federal $n^{\circ} 453$ da Anvisa [7], que exige um mínimo de $95 \%$ de atenuação da radiação $\mathrm{X}$.

Do ponto de vista mecânico, o concreto estudado foi classificado como "normal", seguindo a NBR 8953 [14], propiciando uma estrutura de menor sobrecarga em relação aos seus carregamentos, quando comparadas às estruturas construídas com concretos ou materiais de elevada densidade.

Se tratando do fck (resistência à compressão característica), o concreto estudado está $157 \%$ acima do 
normatizado pela NBR 6118 [15] para pior condição de agressividade, portanto, o mesmo atende com folga as condições de aceitação para fins estruturais.

\section{AGRADECIMENTOS}

À Universidade Católica de Pelotas (UCPel) pela disponibilização do Laboratório de Engenharia Civil (LEC) no qual foi realizada parte das medidas experimentais. Ao Hospital Escola da Universidade Federal de Pelotas (UFPel) administrado pela Empresa Brasileira de Serviços Hospitalares (EBSERH) pela disponibilização do equipamento de raios X. Por fim, à Fundação de Amparo à Pesquisa do Estado do Rio Grande do Sul (FAPERGS) pela concessão da bolsa de iniciação científica ao longo desta pesquisa.

\section{BIBLIOGRAFIA}

[1] PEREIRA, A.J., DANILIAUSKAS, M., LOPES, R.M., Manual para técnicos em radioterapia, 1 ed., Rio de Janeiro, Instituto do Câncer, 2000.

[2] JUNIOR, A.T.A. Caracterização de argamassas de barita como blindagens contra a radiação X $e$ determinação experimental dos coeficientes de atenuação desses materiais. Tese de Doutorado, Programa de Pós-Graduação em Engenharia dos Materiais da REDEMAT, Ouro Preto, MG, Brasil, 2014.

[3] ALBUQUERQUE, S.M. Estudo para o desenvolvimento e caracterização de concretos de massa específica elevada para proteção às radiações gama ex. Tese de Doutorado, Programa de Pós-Graduação em Ciências na área de Tecnologia Nuclear do IPEN-CNEN/SP, São Paulo, SP, Brasil, 2014.

[4] VIGNA FILHO, E.D., FALCÃO, R.C., Blindagem em Radioterapia - Técnicas e Normas, 1 ed., Rio de Janeiro, Instituto Nacional do Câncer, 2000.

[5] HELENE, P., ANDRADE, T., "Concreto de cimento Portland", In: Isaia, G.C. (ed), Materiais em Construção Civil e Princípios de Ciência e Engenharia de Materiais, 2 ed., capítulo 2, São Paulo, Instituto Brasileiro de Concerto. 2010.

[6] REBMANN, M.S. Durabilidade de concretos estruturais com baixo consumo de cimento Portland e alta resistência. Dissertação de Mestrado. Escola de Engenharia de São Carlos da Universidade de São Paulo USP, São Carlos, SP, Brasil, 2011.

[7] AGÊNCIA NACIONAL DE VIGILÂNCIA SANITÁRIA. Portaria Federal $n^{\circ} 453$ de $1^{\circ}$ de junho de 1998. Brasília, DF, Brasil, 1998.

[8] GILL, R., Rochas e processos ígneos: um guia prático. Porto Alegre, Bookman, 2014.

[9] ASSOCIAÇÃO BRASILEIRA DE NORMAS TÉCNICAS. NBR NM 248: Agregados - Determinação da composição granulométrica. Rio de Janeiro, RJ, Brasil, 2003.

[10] DNER-ME, 093/94 Departamento Nacional de Estradas de Rodagem. Solos - Determinação da densidade real. Brasília, DF, Brasil, 1994.

[11] CHRIST, R. Proposição de um método de dosagem para concretos de ultra alto desempenho (UHPC). Tese de Doutorado, Programa de Pós-Graduação em Engenharia Civil da Unisinos, São Leopoldo, RS, Brasil, 2019.

[12] ASSOCIAÇÃO BRASILEIRA DE NORMAS TÉCNICAS. NBR 9479: Argamassa e concreto Câmaras úmidas e tanques para cura de corpos-de-prova. Rio de Janeiro, RJ, Brasil, 2006.

[13] ASSOCIAÇÃO BRASILEIRA DE NORMAS TÉCNICAS. NBR 5739: Concreto - Ensaio de compreensão de corpos de prova cilíndricos. Rio de Janeiro, RJ, Brasil, 2018.

[14] ASSOCIAÇÃO BRASILEIRA DE NORMAS TÉCNICAS. NBR 8953: Concreto para fins estruturais Classificação pela massa específica, por grupos de resistência e consistência. Rio de Janeiro, RJ, Brasil, 2015.

[15] ASSOCIAÇÃO BRASILEIRA DE NORMAS TÉCNICAS. NBR 6118: Projeto de estruturas de concreto - Procedimento. Rio de Janeiro, RJ, Brasil, 2014.

[16] FOX, M. Optical Properties of Solids, $2^{\text {nd }}$ edition, Oxford University Press, 2010. 


\section{ORCID}

Maikon Moreira de Pires

https://orcid.org/0000-0002-0231-9555

Chiara das Dores do Nascimento

Everton Granemann Souza

https://orcid.org/0000-0001-6028-9852

https://orcid.org/0000-0001-9884-6626

Kaiser Kruger

https://orcid.org/0000-0002-1322-9758

Gabriela Hoff

https://orcid.org/0000-0002-7460-8030 